УДК 544.65

\title{
НОВЫЙ ЭЛЕКТРОХИМИЧЕСКИЙ МЕТОД ПОЛУЧЕНИЯ НАНОСТРУКТУРНЫХ Рt/С МАТЕРИАЛОВ
}

\author{
() 2017 И. Н. Новомлинский, В. А. Волочаев, Г. Г. Цветкова, В. Е. Гутерман \\ Южный федеральный университет, ул. Зорге, 7, 344090 Ростов-на-Дону, Россия \\ e-mail:novomlinskij@rambler.ru \\ Поступила в редакцию 17.08.2016 г.
}

\begin{abstract}
Аннотация. Предложен оригинальный способ получения дисперсных Pt/C материалов посредством электроосаждения платины на находящиеся в суспензии частицы углеродного носителя. Материалы изучены методами рентгенографии, гравиметрии, циклической вольтамперометрии и сканирующей электронной микроскопии. Полученные $\mathrm{Pt} / \mathrm{C}$ материалы содержат от 9 до 14 \% масс. Pt. Средний размер частиц платины составляет от 7 до 15 нм, а электрохи-

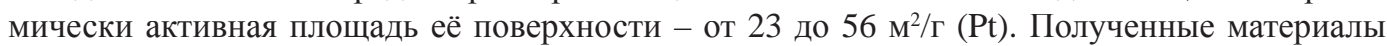
проявляют каталитическую активность в реакции электровосстановления кислорода, которая преимущественно протекает по 4х-электронному механизму.
\end{abstract}

Ключевые слова: электроосаждение, платина, топливные элементы, электрокатализ, электровосстановление кислорода, $\mathrm{Pt} / \mathrm{C}$, наночастицы.

\section{ВВЕДЕНИЕ}

Нанесенные платиноуглеродные материалы вызывают большой интерес, в первую очередь, в связи с их применением в качестве электрокатализаторов в низкотемпературных топливных элементах. Наиболее распространенные способы нанесения наночастиц платины на поверхность дисперсных углеродных носителей (сажа, нанотрубки, нановолокна и др.) относятся к химическим методам, заключающимся в восстановлении платины из ее соединений теми или иными химическими реагентами [1-4]. Химические методы синтеза в жидкой фазе являются достаточно простыми и не требуют дорогостоящего оборудования. В то же время они трудоемки, как правило, характеризуются низкой воспроизводимостью, не позволяют четко контролировать рост наночастиц [5]. Введение в состав раствора ПАВ или органического сорастворителя негативно влияет на характеристики получаемых $\mathrm{Pt} / \mathrm{C}$ катализаторов вследствие адсорбции органических молекул на поверхности и в порах углеродного носителя и последующего влияния на электрохимические реакции.

Весьма перспективными, с точки зрения управления морфологией поверхности катализатора и чистоты получаемого продукта, представляются электрохимические способы получения наночастиц платины [6-7]. Электрохимические процессы мо- гут осуществляться с применением различных режимов электролиза: гальваностатического, потенциостатического, режима переменного тока и т.д. Для контроля роста наночастиц металлов широкие возможности представляет варьирование потенциала и плотности пропускаемого тока. К сожалению, при электроосаждении платины на пористый углеродный слой формирование наночастиц происходит только на его поверхности, но не в глубине [8-10]. В конечном итоге функции катализатора выполняет лишь относительно небольшая «поверхностная» часть слоя пористого электрода. Учитывая, что при получении таких материалов используются микроколичества углеродного порошка, который закрепляется на электрод, в результате электролиза образуются небольшие количества катализатора. Данный факты ставят под вопрос технологичность подобных методик.

Оригинальный электрохимический метод, разработанный Н. В. Смирновой с сотр. [11-15], позволяет получить $\mathrm{Pt} / \mathrm{C}$ материалы путем диспергирования платины. Процесс осуществляется в щелочных растворах под воздействием переменного тока. Авторы методики отводят основную роль в разрушении платины явлению интеркаляции катионов щелочных металлов по межзеренным границам платины. Образующиеся наночастицы закрепляются на поверхности углеродного носителя и 
имеют размер от 5 до 80 нм [12-14]. Стоит заметить, что, разрушаясь, платина образует частицы кубической формы с превалирующей кристаллографической ориентацией $\mathrm{Pt}$ (100) [11]. К сожалению, электрохимически активная площадь поверхности (ЭХАП) Pt/C материалов, полученных таким способом, не превышает 20-25 м²/Г (Pt), что недостаточно для их применения в качестве электрокатализаторов в НТЭ.

Цель настоящей работы состояла в разработке нового метода электрохимического получения $\mathrm{Pt} / \mathrm{C}$ электрокатализаторов, в рамках которого электрокристаллизация частиц платины происходила бы непосредственно на поверхности дисперсных частиц углеродного носителя (Vulcan XC-72), находящихся в углеродной суспензии, выполняющей роль католита.

\section{ЭКСПЕРИМЕНТАЛЬНАЯ ЧАСТЬ}

Для получения Pt/C электрокатализаторов электролиз проводили в гальваностатических условиях при интенсивном перемешивании углеродной суспезии в платиносодержащем электролите (раствор $\mathrm{H}_{2} \mathrm{PtCl}_{6}$ ). В процессе перемешивания микрочастицы углерода время от времени (вероятностный процесс) соприкасались с поверхностью катода. В момент соприкосновения и попадания в прикатодный слой, обеспечивающий подвод электронов к частицам углерода за счет перколяционного эффекта, микрочастицы углерода «превращались» в часть катода, вследствие чего процесс восстановления $\mathrm{Pt}(\mathrm{IV})$ протекал и на их поверхности. За время электролиза каждая частица углеродного носителя неоднократно соприкасалась со стационарным катодом, в результате чего на ее поверхности происходили процессы нуклеации/роста частиц платины. Постоянное обновление микрочастиц углерода в электронопроводящем прикатодном слое, обусловленное искусственной конвекцией, привело к более или менее равномерному распределению электроосажденной платины по поверхности микрочастиц углеродного носителя (смотрите далее). Процесс формирования $\mathrm{Pt} / \mathrm{C}$ материала схематически отображен на рис. 1.

Суспензию получали путем смешения 0.5 г углеродной сажи Vulcan XC-72 (Cabot Corporation, удельная площадь поверхности $270 \mathrm{M}^{2} \cdot \Gamma^{-1}$ ) и 20 мл $1 \mathrm{M}$ раствора $\mathrm{H}_{2} \mathrm{SO}_{4}$ с последующим диспергированием на ультразвуковом гомогенизаторе Sonics в течение 1.5 мин, после чего для сохранения однородности суспензии непрерывно перемешивали на магнитной мешалке. Непосредственно перед началом электролиза суспензию переносили в двухэлектродную ячейку с разделенными электродными пространствами, продолжая перемешивание с помощью магнитной мешалки. После чего концентрированной серной кислотой доводили ее концентрацию в растворе католита до 1 моль/л. Анодное пространство заполняли $1 \mathrm{M}$ раствором $\mathrm{H}_{2} \mathrm{SO}_{4}$. Далее в катодное пространство вносили 2 мл $0.01 \mathrm{M} \mathrm{H}_{2} \mathrm{PtCl}_{6}$. В качестве катода использовали медную проволоку, в качестве анода - графитовый стержень. Электролиз вели в режиме постоянного тока. Для поддержания постоянства концентрации $\mathrm{Pt}(\mathrm{IV})$ в растворе в прикатодное пространство в течение электролиза периодически добавляли по 2 мл $0.01 \mathrm{M} \mathrm{H}_{2} \mathrm{PtCl}_{6}$. Общее количество $0.01 \mathrm{M}$ раствора $\mathrm{H}_{2} \mathrm{PtCl}_{6}$, добавленного в процессе электроосаждения, составляло 8 мл.

После окончания электролиза суспензию Pt/C фильтровали, затем многократно промывали бидистиллированной водой. Осушку вели в эксикаторе над $\mathrm{P}_{2} \mathrm{O}_{5}$ при комнатной температуре.

Для определения состава полученных образцов $\mathrm{Pt} / \mathrm{C}$ и наличия в них наночастиц платины исполь-

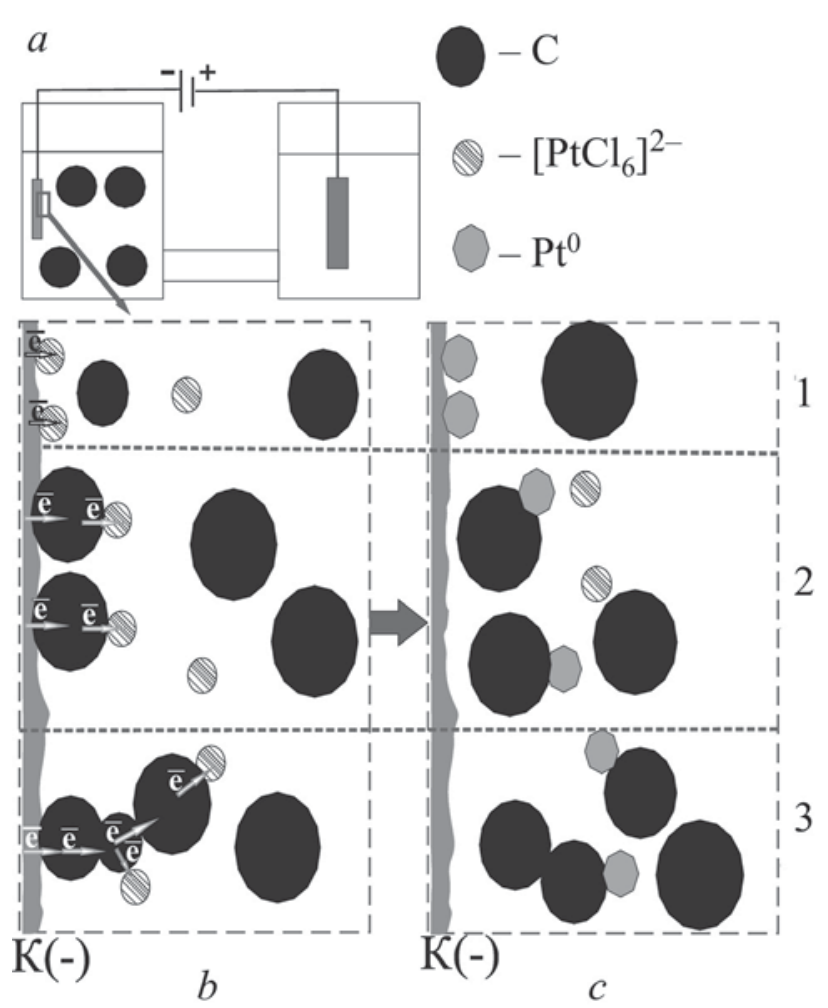

Рис. 1. Схематическое изображение установки $(a)$ и процесса $(b-c)$ электрохимического получения $\mathrm{Pt} / \mathrm{C}$ материалов

[Fig. 1. Schematic representation of the electrochemical cell $(a)$ and the process $(b-c)$ of electrochemical preparation of $\mathrm{Pt} / \mathrm{C}$ materials] 
зовали рентгенофазовый анализ и термогравиметрию. Порошковые дифрактограммы металлуглеродных материалов регистрировали на автоматическом дифрактометре ARL X'TRA (геометрия по Бреггу-Брентано, радиус 260 мм, вертикальный тета-тета гониометр) с использованием $\mathrm{CuK \alpha -из-}$ лучения ( $\lambda=1.5418 \AA)$. Типичные установки: 40 кВ, 30 мА, шаг сканирования 0.02 тета. Скорость съёмки 8 градусов в минуту для простого рентгенофазового анализа. В качестве калибровочного стандарта использовали стандартную пластину поликристаллического альфа-кварца.

По полученным дифрактограммам определяли наличие платины в материале и средний размер (диаметр) её кристаллитов - $D$. Расчет $D$ проводили по формуле Шеррера (1), в которую подставляли значение ширины пика 111 на половине его высоты:

$$
D=K \lambda /(F W H M \cdot \cos \theta),
$$

где $\lambda$ - длина волны монохроматического излучения, $\mathrm{E} ; F W H M$ - ширина пика на полувысоте (в радианах); $D$ - средний размер кристаллитов, нм; $\theta$ - угол отражения, радианы; $K=0.89$ - постоянная Шеррера.

Массовую долю платины $(\omega(\mathrm{Pt}))$ в $\mathrm{Pt} / \mathrm{C}$ определяли методом термогравиметрии по массе остатка (Pt) после сжигания $\left(800^{\circ} \mathrm{C}, 40\right.$ мин).

Для определения электрохимической активной площади поверхности (ЭХАП) платины использовали метод циклической вольтамперометрии. Тонкий (около 4 мкм) слой каждого $\mathrm{Pt} / \mathrm{C}$ материала наносили на торец вращающегося дискового электрода. Для этого 6 мкл суспензии $\mathrm{Pt} / \mathrm{C}$ в смеси вода - изопропанол, содержащей добавку полимеpa Nafion, наносили на торец стеклографитового вращающегося дискового электрода (ВДЭ). После сушки для закрепления слоя наносили еще 7 мкл $0.05 \%$ раствора Nafion, после чего электрод высушивали 5 минут при комнатной температуре. С помощью потенциостата AFCBP1 (Pain Applied Instrumentation) задавали развертку потенциала и фиксировали значения тока. Первоначально для стандартизации поверхности Pt и полного удаления примесей проводили 100 циклов развертки потенциала со скоростью $200 \mathrm{MB} \cdot \mathrm{c}^{-1}$ в диапазоне потенциалов от 0 до 1.2 В (относительно СВЭ). Далее регистрировали 2 циклических вольтамперограммы (ЦВА) в диапазоне потенциалов 0-1.2 В при скорости развертки $20 \mathrm{MB} \cdot \mathrm{c}^{-1}$. Затем по количеству электричества, затраченному на электрохимическую адсорбцию и десорбцию атомарного водорода, проводили расчет ЭХАП, как это описано в [16].

Для оценки активности катализаторов в реакции электровосстановления кислорода (РВК) проводили измерение серии вольтамперограмм с линейной разверткой потенциала в диапазоне от 0.02 до 1.2 В и скоростью развертки 20 мВ c $^{-1}$ при скоростях вращения электрода 400, 900, 1600 и 2500 об мин $^{-1}$.

Микроструктуру образцов изучали методом сканирующей электронной микроскопии с полевой эмиссией (FE-SEM) на электронном микроскопе Hitachi SU8000. Съемку изображений вели в режимах регистрации вторичных и отраженных электронов при ускоряющем напряжении 5 кВ и рабочем расстоянии 9-10 мм, как это описано в [17].

\section{РЕЗУЛЬТАТЫ И ОБСУЖДЕНИЕ}

Для изучения микроструктуры Pt/C материалов и их электрохимического поведения были выбраны три образца, при получении которых электролиз проводили при температурах $35,50,65^{\circ} \mathrm{C}$, пропуская 900 кулон электричества. Выход по току (кулоновская эффективность) при получении продукта составлял от 10 до $18 \%$. Отметим, что в процессе электролиза на катоде наблюдалось бурное выделение водорода. Поэтому нельзя исключить, что некоторая часть платины, осажденной на поверхность углеродного носителя, могла образоваться в результате химического восстановления $\mathrm{Pt}(\mathrm{IV})$ выделяющимся водородом, а не за счет электровосстановления. Ниже приведены сведения (табл. 1) о

Таблица 1. Некоторые характеристики полученных $\mathrm{Pt} / \mathrm{C}$ материалов

[Table 1. Some characteristics of $\mathrm{Pt} / \mathrm{C}$ materials]

\begin{tabular}{|c|c|c|c|}
\hline $\begin{array}{c}\text { Температура электролита при } \\
\text { электроосаждении платины } \\
\text { [Temperature of the electrolyte in } \\
\text { the electrodeposition of platinum] }\end{array}$ & $\omega(\mathrm{Pt}), \%$ & $\begin{array}{c}\text { ЭХАП, }{ }^{2} \Gamma^{-1}(\mathrm{Pt}) \\
{\left[\mathrm{ESA}, \mathrm{m}^{2} \mathrm{~g}^{-1}(\mathrm{Pt})\right]}\end{array}$ & $\begin{array}{c}\text { Средний диаметр } \\
\text { кристаллитов, } D, \mathrm{Hм} \\
{\left[D_{\mathrm{Av}}, \mathrm{nm}(\mathrm{XRD})\right]}\end{array}$ \\
\hline 65 & 14 & 23 & 15 \\
\hline 50 & 13 & 45 & 10 \\
\hline 35 & 9 & 56 & 7 \\
\hline
\end{tabular}


некоторых характеристиках полученных катализаторов.

На рентгенограммах синтезированных образцов (рис. 2) четко видны характерные для поликристаллической платины отражения, что подтверждает наличие фазы металлической платины. Расчет, проведенный по формуле Шеррера, показал, что $D$ кристаллитов платины в зависимости от условий (температуры) электроосаждения составляет от 7 до 15 нм (табл. 1).

Массовая доля платины в полученных образцах растет от 9 до 14\% масс. по мере увеличении температуры электролита от 35 до $60{ }^{\circ} \mathrm{C}$ (табл. 1). Это может быть обусловлено как непосредственным влиянием температурного режима, так и изменением силы тока при электролизе. Дело в том, что увеличение электропроводности электролита с ростом температуры позволило увеличить силу тока от 4 А (при $35^{\circ} \mathrm{C}$ ) до 9.5 А (при $60^{\circ} \mathrm{C}$ ), сократив при этом время электролиза. В результате повысился выход по току и, как следствие, загрузка платины в Pt/C материале.

ЦВА полученных образцов имеют характерную для $\mathrm{Pt} / \mathrm{C}$ материалов форму, но различаются по абсолютным значениям силы тока (рис. 3). Сравнительно небольшие значения токов в водородной и кислородной областях ЦВА в сочетании с широкой двойнослойной областью (относительно высокими значениями силы тока в диапазоне потенциалов примерно от 0.3 до 0.7 В) обусловлены низкой массовой долей Pt и, как следствие, значительным вкладом в суммарное значение силы тока процессов, протекающих на углероде. Величина ЭХАП синтезированных Pt/C материалов, рассчитанная по водородной области ЦВА, варьируется в пределах от 23 до 56 м²/г (Pt) в зависимости от условий получения материалов и загрузки в них платины (табл. 1). Значения силы тока, отнесенные к массе осажденной $\mathrm{Pt}(\mathrm{A} / \Gamma(\mathrm{Pt}))$, как и следовало ожидать, максимальны для электрокатализатора с наименьшей загрузкой Pt и наибольшей ЭХАП (рис. 3). Это означает, что удельная каталитическая активность поверхности $\mathrm{Pt}$ близка во всех полученных образцах, поэтому массактивность определяется именно величиной ЭХАП. Действительно, при регистрации серии вольтамперограмм с линейной разверткой потенциала на ВДЭ скорость реакции электровосстановления кислорода (масс-активность катализатора) была наибольшей в случае катализатора, полученного при $35^{\circ} \mathrm{C}$ (рис. 36). Расчет количества электронов, участвующих в реакции, проводили с использованием уравнения Коутецкого-Јевича [18]:

$$
\begin{gathered}
1 / i=1 / i_{\text {к }}+1 / i_{\text {д }}=1 / i_{\text {к }}+1 / Z \omega^{0.5}, \\
Z=0.62 n F D^{2 / 3} v^{-1 / 6} c,
\end{gathered}
$$

где $i$ - ток на дисковом электроде, А $\mathrm{cm}^{-2} ; i_{\kappa}$ - кинетический ток, А·см ${ }^{-2} ; i_{\partial}-$ диффузионный ток, А $\mathrm{cm}^{-2} ; \omega$-скорость вращения дискового электрода $\left(\right.$ рад· $\left.{ }^{-1}\right) ; n-$ количество электронов, участвующих в реакции электровосстановления молекулы кислорода; $F$ - постоянная Фарадея, Кл-моль ${ }^{-1}$; $D$ - коэффициент диффузии, $\mathrm{cm}^{2} \cdot \mathrm{c}^{-1} ; v-$ кинемати-

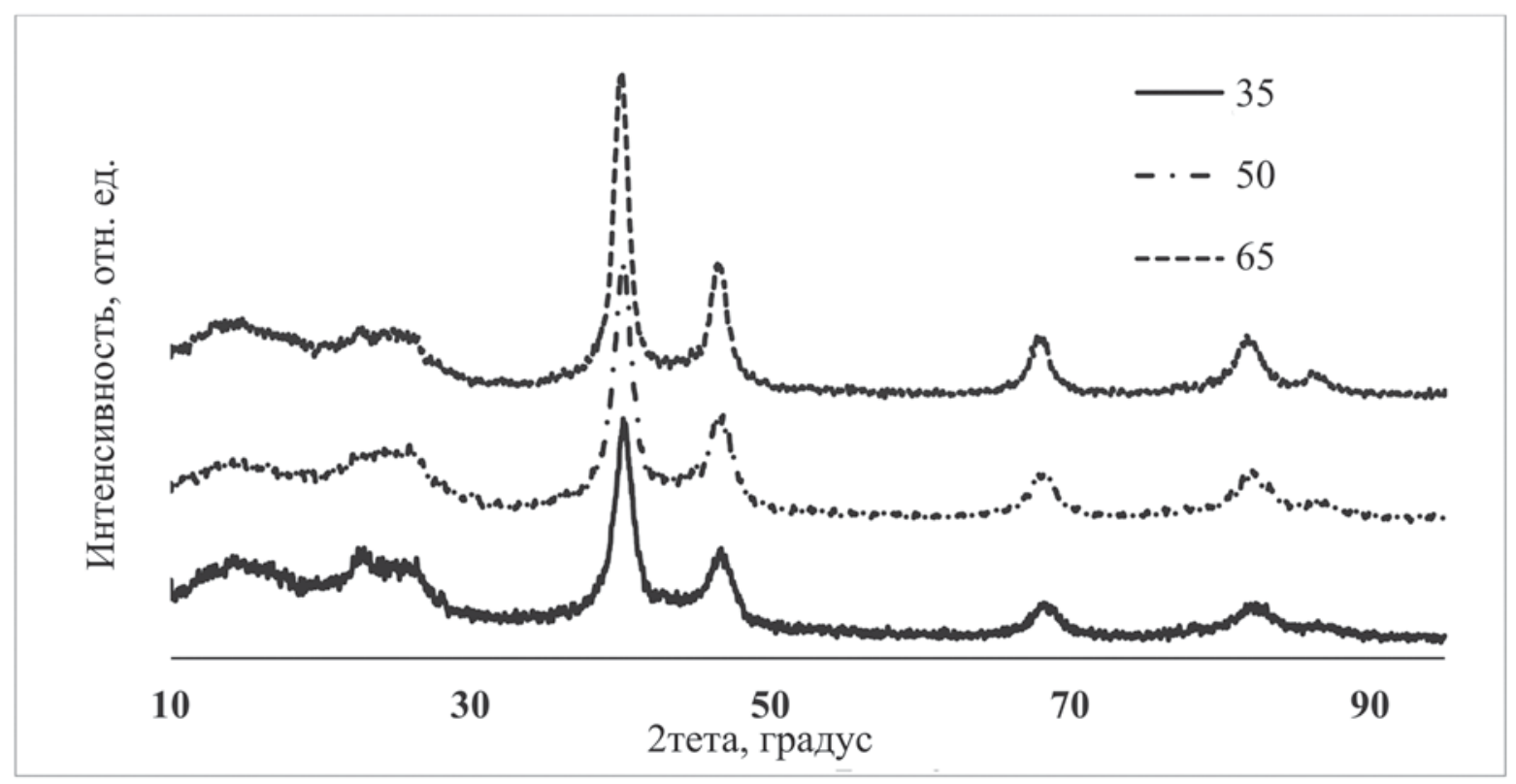

Рис. 2. Дифрактограммы $\mathrm{Pt} / \mathrm{C}$ образцов

[Fig. 2. XRD patterns of Pt/C samples] 

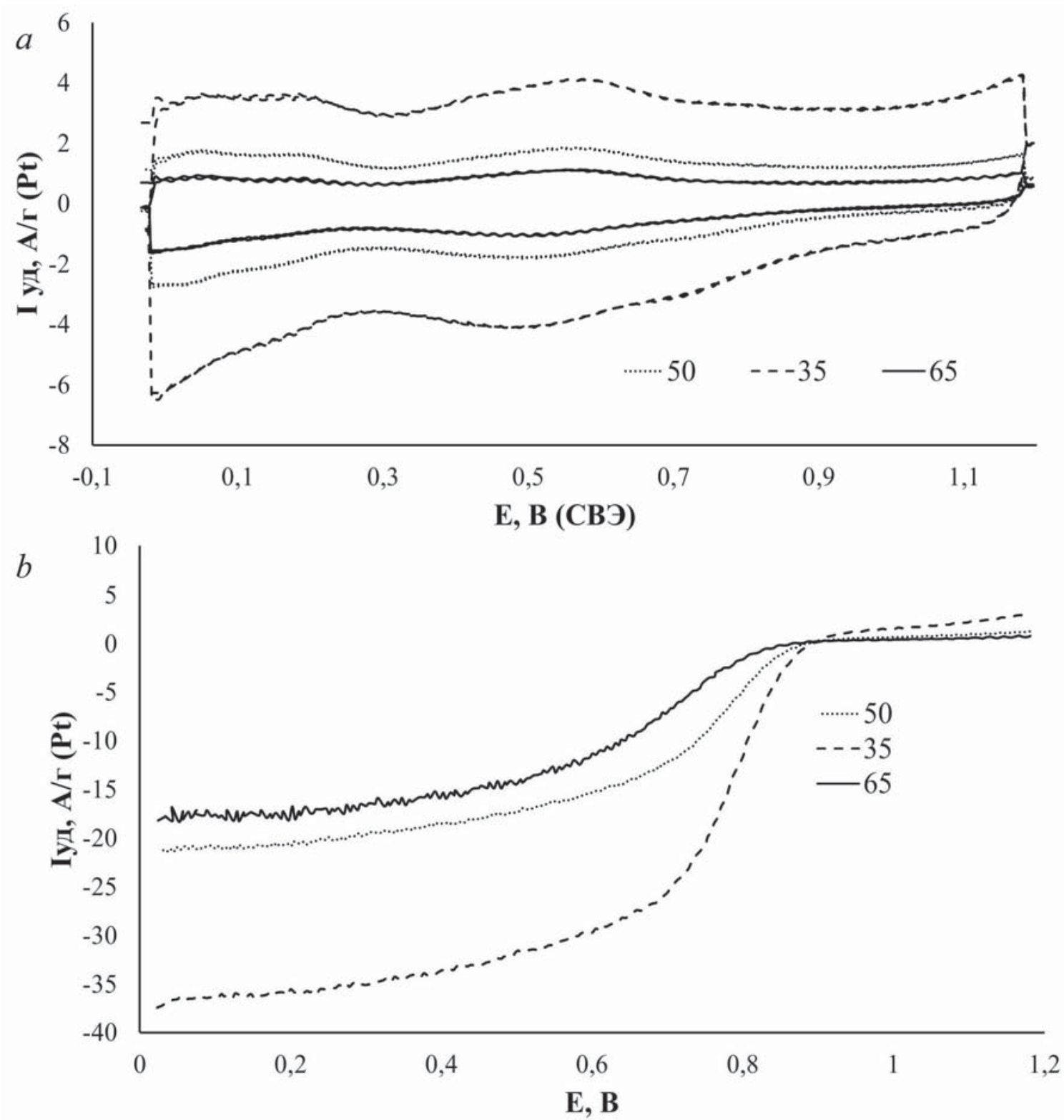

Рис. 3. $a$ - Циклические вольтамперограммы, зарегистрированные на стандартизированной поверхности образцов $\mathrm{Pt} / \mathrm{C}$ катализаторов. $0.1 \mathrm{M} \mathrm{HClO}_{4}$, атм. Ar. Скорость развертки потенциала $-20 \mathrm{MB} \cdot \mathrm{c}^{-1} ; b-$ вольтамперограммы с линейной разверткой потенциала при электровосстановлении кислорода. $0.1 \mathrm{M} \mathrm{HClO}_{4}$, атм. О. Скорости вращения дискового электрода - 1600 об·мин ${ }^{-1}$. Скорость развертки потенциала $-20 \mathrm{MB} \cdot \mathrm{c}^{-1}$

[Fig. 3. $a$ - Cyclic voltammograms recorded on a standardized surface of Pt/C catalysts. 0.1 $\mathrm{M} \mathrm{HClO}_{4}$, Ar atmosphere. A potential sweep rate is $20 \mathrm{mV} \cdot \mathrm{s}^{-1}$; $b$ is voltammograms of oxygen electroreduction with the linear sweep rate of potential $20 \mathrm{mV} \cdot \mathrm{s}^{-1}$. $0.1 \mathrm{M} \mathrm{HClO}_{4}, \mathrm{O}_{2}$ atmosphere. $\mathrm{RDE}$ rotation speed is $\left.1600 \mathrm{rpm}\right]$

ческая вязкость электролита, $\mathrm{cm}^{2} \cdot \mathrm{c}^{-1} ; c$ - концентрация кислорода в растворе, моль см$^{-3}$.

По результатам расчета на всех исследованных $\mathrm{Pt} / \mathrm{C}$ катализаторах величина $\mathrm{n}$ находилась в диапазоне 3.5-4.0, что свидетельствует об электровосстановлении кислорода преимущественно по 4-х электронному механизму.

СЭМ изображения полученных материалов (рис. 4) свидетельствуют о равномерном распреде- лении наночастиц платины по поверхности микрочастиц углеродного носителя. Определить точный размер и размерное распределение частиц платины по данным СЭМ-микроскопии представляется затруднительным, однако очевидно, что в материале присутствуют частицы, размер которых значительно превышает 10 нм. Имеются также агрегаты наночастиц. Высокие значения ЭХАП платины (46-55 м $\left.{ }^{2} \Gamma^{-1}(\mathrm{Pt})\right)$ при такой морфологии осадка 


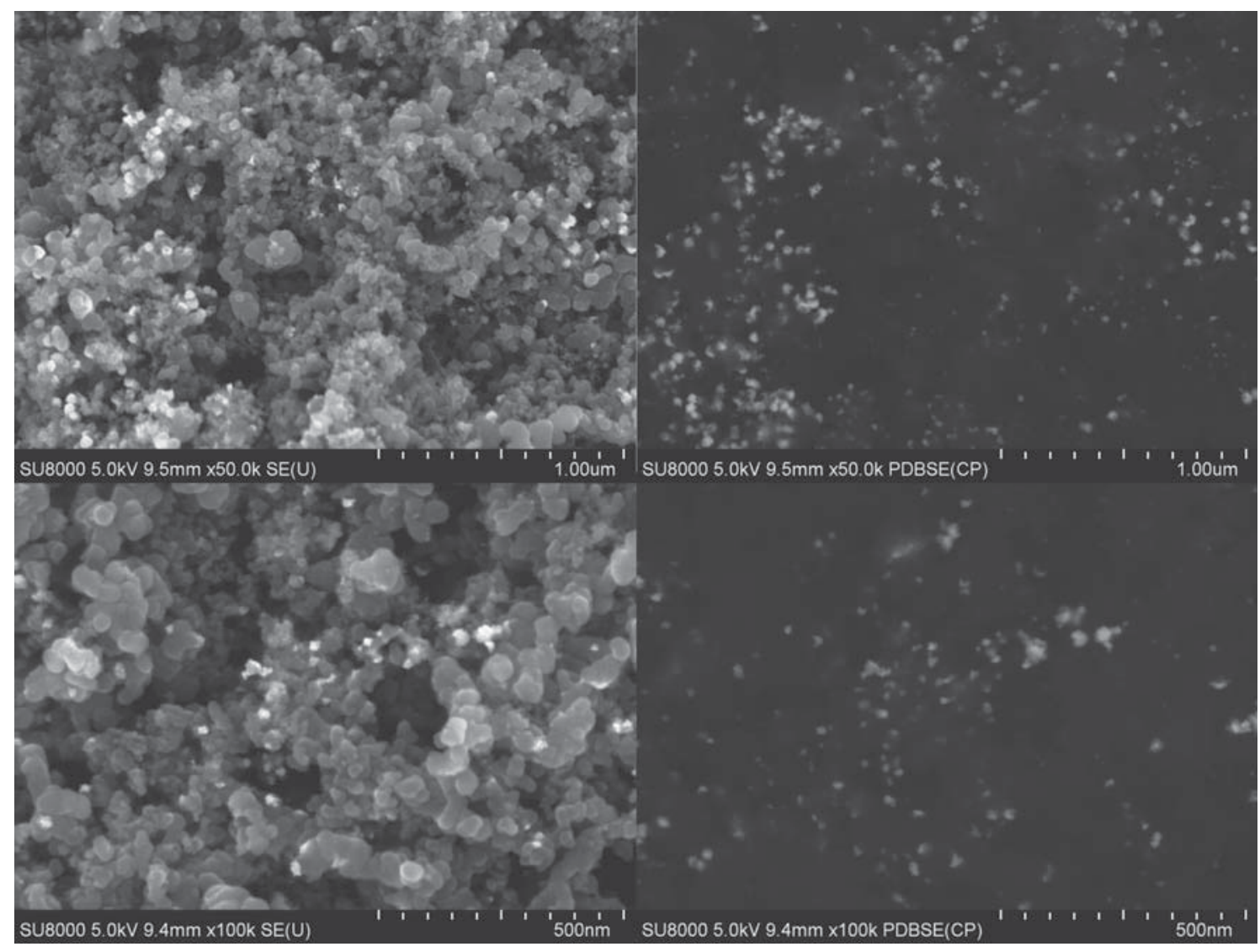

$a$

$b$

Рис. 4. Фотография поверхности образца $\mathrm{Pt} / \mathrm{C}$, полученная методом сканирующей электронной микроскопии в режиме съемки вторичных $(a)$ и отраженных $(b)$ электронов

[Fig. 4. SEM photographs of the Pt/C sample surface, obtained in the modes of secondary $(a)$ and reflected $(b)$ electrons]

можно объяснить лишь в предположении о развитой поверхности частиц, состоящих из нескольких сросшихся кристаллитов. Отметим, что развитая поверхность с высокой шероховатостью характерна для электролитических осадков платины. Так, например, в [10, 19] методом гальваностатического электроосаждения на закрепленный слой дисперсного углеродного носителя Vulcan XC-72 были получены наночастицы платины хлопьевидной формы и сферолиты с развитой поверхностью.

\section{ЗАКЛЮЧЕНИЕ}

Предложен оригинальный метод получения дисперсных Pt/C материалов посредством электроосаждения платины на находящиеся в суспензии частицы углеродного носителя. Полученные $\mathrm{Pt} / \mathrm{C}$ материалы содержат от 9 до $14 \%$ масс. Pt и проявляют каталитическую активность в РВК. Электровосстановление кислорода на полученных катализаторах преимущественно протекает по характерному для платины 4x-электронному механизму.
Размер большинства частиц осажденной платины, значительная часть которых состоит из нескольких сросшихся кристаллитов, превышает 7-10 нм. Тем не менее, величины ЭХАП осадков весьма высоки

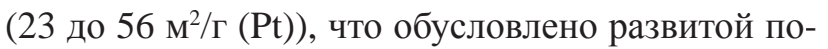
верхностью частиц платины.

Учитывая широкие возможности методов электрокристаллизации по управлению процессами нуклеации/роста новой фазы и, как следствие, морфологией осадка, предложенный нами метод представляется весьма перспективным для получения дисперсных $\mathrm{Pt} / \mathrm{C}$ материалов, в том числе и электрокатализаторов для низкотемпературных топливных элементов.

Работа выполнена при финансовой поддержке Южного федерального университета (грант 213.01.-07.2014/10ПЧВГ). Авторы благодарят отдел структурных исследований ИОХ РАН за исследование образиов методом сканирующей электронной микроскопии. 


\section{СПИСОК ЛИТЕРАТУРЫ}

1. Zhang J., Wang X., Wu C., et al. // React. Kinet. Catal. Lett, 2004. vol. 83. № 2. pp. 229-236.

2. Chen J., Jiang C., Yang X., et al. // Electrochem. Comm., 2011, vol. 13, pp. 314-316.

3. Prabhuram J., Zhao T. S., Wong C. W., et al. // J. of Power Sources. 2004, vol. 134, pp. 1-6.

4. Алексеенко А. А., Гутерман В. Е., Волочаев В. А., Беленов С. В. // Неорган. материаль, 2015, т. 51, № 12, c. $1355-1360$.

5. Thompsett D. // Handbook of Fuel Cells. Fundamentals, Technology and Applications. 2003, vol. 3, (Chapter 6) p. 6-1-6-23. 193.

6. Петрий О. А. // Успехи химии, 2015, т. 84, с. 159-

7. Беленов С. В., Гебретсадик В. Й., Гутерман В. Е., Скибина Л. М., Лянгузов Н. В. // Инженерный вестник Цона, 2014, т. 30, № 2, с. 9.

8. Wei Z. D., Chan S. H., Li L. L., Cai H. F., Xia Z. T., Sun C. X. // Electrochim. Acta, 2005, vol. 50, pp. 22792287.

9. Santiago D., Rodryguez-Calero G. G., Rivera H., Tryk D. A., Scibioh M. A., Cabrera C. R. // J. Electrochem. Soc., 2010, vol. 157, pp. F189-F195.

10. Weldegebriel Yohannes, Belenov S. V., Guterman V. E., Skibina L. M., Volotchaev V. A., Lyanguzov N. V. // J. Appl. Electrochem., 2015, vol. 45, pp. 623-633.
11. Смирнова Н. В., Куриганова А. Б. // Инженерный вестник Дона, 2011, т. 15, № 1, с. 310-314.

12. Куриганова А. Б., Герасимова Е. В., Леонтьев И. Н., Смирнова Н. В., Добровольский Ю. А. // Международный научный журнал “Альтернативная энергетика и экология”, 2011, № 5, с. 58-62.

13. Липкин М. С., Смирнова Н. В., Куриганова А. Б. // Инженерный вестник Дона, 2012, т. 19, № 1, c. $60-64$.

14. Леонтьева Д. В., Леонтьева Д. В., Смирнова Н. В. // Международный научный журнал “Альтернативная энергетика и экология”, 2012, № 10, с. 5963.

15. Leontyeva D. V., Smirnova N. V., Leontyev I. N., Avramenko M. V., Yuzyuk Y. I., Kukushkina Yu. A. // Electrochimica Acta., 2013. vol. 114. pp. 356-362.

16. Guterman V. E., Pakharev A. Y., Tabachkova N. Y. // Appl. Catal. A: General., 2013, vol. 453, pp. 113-120.

17. Качала В. В., Хемчян Л. Л., Кашин А. С., Орлов Н. В., Грачев А. А., Залесский С. С., Анаников В. П. // Успехи химии, 2013, т. 82, 648-685.

18. Min Ku Jeon, Yuan Zhang, Paul J. McGinn // Electrochimica Acta, 2010, vol. 55, pp. 5318-5325

19. Беленов С. В., Гебретсадик В. Й., Гутерман В. Е., Скибина Л. М., Лянгузов Н.В. // Конденсированные среды и межфазные границы, 2015, т. 17, № 1, с. 3749.

\title{
NEW ELECTROCHEMICAL METHOD FOR THE PREPARATION OF Pt/C NANOSTRUCTURED MATERIALS
}

\author{
(C) 2017 I. N. Novomlinskij, V. A. Volochaev, G. G. Tsvetkova, V. E. Guterman \\ Southern Federal University, 7 Zorge str., 344090 Rostov-on-Don, Russia \\ e-mail: novomlinskij@rambler.ru
}

Received 17.08.2016

\begin{abstract}
The original method for the preparation of dispersed Pt/C materials by means of platinum electrodeposition on the carbon particles in suspension has been proposed. The electrolysis was carried in galvanostatic conditions with vigorous stirring carbon suspension in platinum electrolyte. In the process of mixing microparticles of carbon occasionally have been in contact with the surface of the cathode. At the time of contact and getting into the cathode layer, providing a supply of electrons to the carbon particles due to the percolation effect, the microparticles of carbon "turned" into a part of the cathode, owing to what process of restitution of ions of platinum proceeded on their surface. The materials were studied by X-ray, thermogravimetry, cyclic voltammetry and scanning electron microscopy. The resulting Pt/C materials contain from 9 to $14 \mathrm{wt}$ \% Pt. On the diffraction patterns of the synthesized samples clearly expressed characteristic reflections for polycrystalline platinum, which confirms the presence of the metallic phase of platinum. The calculation showed that the average size of the crystallites of platinum, depending on the conditions of the electrolysis is from 7 to $15 \mathrm{~nm}$. The value of electrochemically active surface area of the synthesized $\mathrm{Pt} / \mathrm{C}$ materials, designed for the hydrogen region of the cyclic voltamperometry, ranging from 23 to $56 \mathrm{~m}^{2} / \mathrm{g}(\mathrm{Pt})$, depending on the conditions of obtaining materials and load platinum in them. The resulting materials exhibit catalytic activity in the oxygen electroreduction reaction which predominantly flows through 4-electron mechanism. Given the opportunities of the methods of electrocrystallization management processes of nucleation / growth of a new phase and, as a consequence, morphology of precipitate, our proposed method seems very promising for obtaining a dispersed $\mathrm{Pt} / \mathrm{C}$ materials and electrocatalysts for low temperature fuel cells.
\end{abstract}


Keywords: electrodeposition, platinum, fuel cells, electrocatalysis, oxygen electroreduction, $\mathrm{Pt} / \mathrm{C}$, nanoparticles.

\section{ACKNOWLEDGEMENTS}

The work was supported by the Southern Federal University (grant 213.01.-07.2014/10ПЧВГ). The authors thank the Department of Structural Research of the Kurnakov Institute of General and Inorganic Chemistry of the Russian Academy of Sciences (IGIC RAS) for the study of samples by the method of scanning electron microscopy

\section{REFERENCES}

1. Zhang J., Wang X., Wu C., et al. React. Kinet. Catal. Lett., 2004, vol. 83, no. 2, pp. 229-236. DOI: 10.1023/B: REAC.0000046081.96554.ae

2. Chen J., Jiang C., Yang X., et al. Electrochem. Comm., 2011, vol. 13, pp. 314-316. DOI:10.1016/j.elecom.2011. 01.012

3. Prabhuram J., Zhao T. S., Wong C. W., et al. J. of Power Sources, 2004, vol. 134, pp. 1-6. DOI:10.1016/j. jpowsour.2004.02.021

4. Alekseenko A. A., Guterman V. E., Volochaev V. A., Belenov S. V. Inorganic Materials, 2015, vol. 51, no. 12, pp. 1258-1353. DOI: 10.1134/S0020168515120018

5. Thompsett D. Handbook of Fuel Cells. Fundamentals, Technology and Applications. 2003, vol. 3, (Chapter 6) pp. 6-1-6-23.

6. Petrii O. A. Russ. Chem. Rev., 2015, vol. 84, pp. 159193 DOI: $10.1070 /$ RCR4438

7. Belenov S. V., Gebretsadik V. I., Guterman V. E., Skibina L. M., Lyanguzov N. V. Engineering Journal of Don, 2014, vol. 30, no. 2, 9 p. (in Russian)

8. Wei Z. D., Chan S. H., Li L. L., Cai H. F., Xia Z. T., Sun C. X. // Electrochim. Acta, 2005, vol. 50, pp. 2279-2287. DOI:10.1016/j.electacta.2004.10.054

9. Santiago D., Rodryguez-Calero G. G., Rivera H., Tryk D. A., Scibioh M. A., Cabrera C. R. J. Electrochem.
Soc., 2010, vol. 157, pp. F189-F195. DOI:10.1149/ 1.3489948

10. Weldegebriel Yohannes, Belenov S. V., Guterman V. E., Skibina L. M., Volotchaev V. A., Lyanguzov N. V. J. Appl. Electrochem., 2015, vol. 45, pp. 623-633. DOI: $10.1007 / \mathrm{s} 10800-015-0820-5$

11. Smirnova N. V., Kuriganova A. B. Engineering Journal of Don, 2011, vol. 15, no. 1, pp. 310-314. (in Russian)

12. Kuriganova A. B., Gerasimova E. V., Leont'ev I. N., Smirnova N. V., Dobrovol'skii Yu. A. International Scientific Journal for Alternative Energy and Ecology, 2011, no. 5, pp. 58-62.

13. Lipkin M.S., Smirnova N. V., Kuriganova A. B. Engineering Journal of Don, 2012, vol. 19, no. 1, pp. 6064.

14. Leont'eva D. V., Leont'eva D. V., Smirnova N. V. International Scientific Journal for Alternative Energy and Ecology, 2012, no. 10, pp. 59-63.

15. Leontyeva D. V., Smirnova N. V., Leontyev I. N., Avramenko M. V., Yuzyuk Y. I., Kukushkina Yu. A. Electrochimica Acta., 2013. vol. 114. pp. 356-362. DOI: 10.1016/ j.electacta.2013.10.031

16. Guterman V. E., Pakharev A. Y., Tabachkova N. Y. Appl. Catal. A: General., 2013, vol. 453, pp. 113-120.

17. Kachala V. V., Khemchyan L. L., Kashin A. S., Orlov N. V., Grachev A. A., Zalesskii S. S., Ananikov V. P. Russ. Chem. Rev., 2013, vol. 82, pp. 648-685 DOI: 10.1070/ RC2013v082n07ABEH004413

18. Min Ku Jeon, Yuan Zhang, Paul J. McGinn. Electrochimica Acta, 2010, vol. 55, p. 5318-5325. DOI:10.1016/ j.electacta.2010.04.056

19. Belenov S. V., Gebretsadik V. I., Guterman V. E., Skibina L. M., Lyanguzov N. V. Condensed Matter and Interphases, 2015, vol. 17, тo. 1, pp. 37-49. Available at: http://www.kcmf.vsu.ru/resources/t_17_1_2015_005.pdf

Novomlinskij Ivan N. - post-graduate student of Chemistry Department, Southern Federal University; ph.: +7 (863) 2975151, e-mail: novomlinskij@ rambler.ru

Volochaev Vadim A. - Cand. Sci. (Chem.), Researcher, Chemistry Department, Southern Federal University; ph.: +7 (863) 2975151, e-mail: v.a.volotchaev@mail.ru

Tsvetkova Galina G. - student of Chemistry Department, Southern Federal University; ph.: +7 (863) 2975151, e-mail: galina.cvetkova.94@mail.ru

Guterman Vladimir E. - Dr. Sci. (Chem.), Professor, Chemistry Department, Southern Federal University; ph.: +7 (863) 2975151, e-mail: guter@sfedu.ru 